\title{
LIMPRINT Study: The Turkish Experience
}

\author{
Pinar Borman, MD, ${ }^{1,2}$ Christine Moffatt, CBE, PhD, MA, ${ }^{3}$ Susie Murray, MA, ${ }^{4}$ Aysegul Yaman, MD, ${ }^{1}$ \\ Merve Denizli, MD, ${ }^{1}$ Meltem Dalyan, MD, ${ }^{5}$ Sibel Unsal-Delialioğlu, MD, ${ }^{5}$ Sibel Eyigör, MD, ${ }^{6}$ Figen Ayhan, MD, \\ Burcu Duyur Çakıt, MD, ${ }^{5}$ Secil Vural, MD, ${ }^{5}$ Oya Özdemir, MD, ${ }^{1,2}$ Eda Kurt, MD, \\ Evrim Coşkun Çelik, MD, ${ }^{8}$ Lale Cerrahoğlu, MD, ${ }^{9}$ Müge Kepekçi, MD, ${ }^{10}$ \\ Fusun Terzioğlu, RN, MSc, PhD, ${ }^{11}$ and Ayşe Arikan Donmez, PhD ${ }^{2,12}$
}

\section{Abstract}

Background: Lymphedema and chronic edema is a major health care problem in both developed and nondeveloped countries The Lymphoedema Impact and Prevelance - International (LIMPRINT) study is an international health service-based study to determine the prevalence and functional impact in adult populations of member countries of the International Lymphoedema Framework (ILF).

Methods and Results: A total of 1051 patients from eight centers in Turkey were recruited using the LIMPRINT study protocol. Data were collected using the core and module tools that assess the demographic and clinical properties as well as disability and quality of life $(\mathrm{QoL})$. Most of the Turkish patients were recruited from specialist lymphedema services and were found to be women, housewives, and having secondary lymphedema because of cancer treatment. The duration of lymphedema was commonly $<5$ years and most of them had International Society of Lymphology (ISL) grade 2 lymphedema. Cellulitis, infection, and wounds were uncommon. The majority of patients did not get any treatment or advice before. Most of the patients had impaired QoL and decreased functionality, but psychological support was neglected. Although most had social health security access to lymphedema centers, nevertheless access seemed difficult because of distance and cost.

Conclusion: The study has shown the current status and characteristics of lymphedema patients, treatment conditions, the unmet need for the diagnosis and treatment, as well as burden of the disease in both patients and families in Turkey. National health policies are needed for the prevention, diagnosis, and treatment in Turkey that utilize this informative data.

Keywords: lymphedema, lymphoedema, chronic edema, LIMPRINT, quality of life, impact

\footnotetext{
${ }^{1}$ Department of Physical Medicine and Rehabilitation (PMR), University of Hacettepe Faculty of Medicine, Ankara, Turkey.

${ }^{2}$ Lymphedema Research and Practice Center, Hacettepe University, Ankara, Turkey.

${ }^{3}$ Department of Nursing, School of Social Sciences, Nottingham Trent University, Nottingham, United Kingdom.

${ }^{4}$ CRICP, London, United Kingdom.

${ }^{5}$ Department of Physical Medicine and Rehabilitation (PMR), Ankara Physical Medicine and Rehabilitation Training and Research Hospital, Ankara, Turkey.

${ }^{6}$ Department of Physical Medicine and Rehabilitation (PMR), Faculty of Medicine, University of Ege, Izmir, Turkey.

${ }^{7}$ Department of Physical Medicine and Rehabilitation (PMR), Faculty of Medicine, University of Ahi Eṿran, Kırşehir, Turkey.

${ }^{8}$ Department of Physical Medicine and Rehabilitation (PMR), İstanbul Training and Research Hospital, Istanbul, Turkey.

${ }^{9}$ Department of Physical Medicine and Rehabilitation (PMR), Faculty of Medicine, University of Celal Bayar, Manisa, Turkey.

${ }^{10}$ Department of Physical Medicine and Rehabilitation (PMR), Kanuni Sultan Süleyman Training and Research Hospital, İstanbul, Turkey.

${ }^{11}$ Department of Nursing, Faculty of Health Science, Atılım University, Ankara, Turkey.

${ }^{12}$ Department of Internal Medicine Nursing, University of Hacettepe Faculty of Nursing, Ankara, Turkey.
}

(c) Pinar Borman et al. 2019; Published by Mary Ann Liebert, Inc. This Open Access article is distributed under the terms of the Creative Commons License (http://creativecommons.org/licenses/by/4.0), which permits unrestricted use, distribution, and reproduction in any medium, provided the original work is properly cited. 


\section{Introduction}

$\mathbf{L}$ YMPHEDEMA IS AN incurable, debilitating, and progressive condition, characterized by persistent swelling of one or more parts of the body, because of the impairments in lymph transport. This chronic and progressive disease can occur at any time after cancer surgeries, can arise from congenital malformation of the lymphatic system, or because by damage to lymphatic vessels. ${ }^{1,2}$ It is a major health care problem in both developed and nondeveloped countries. It is serious because of its long-term physical and psychosocial consequences for the patients, if left untreated. When lymphedema is not diagnosed and treated in the earlier stages, the prognosis for these patients is worse and treatments are more costly. Lymphedema frequently leads to physical, emotional,

Table 1. The Core Data of Turkish Patients COMPRISING THE DEMOGRAPHIC and Disease-Related Variables $(N=051)$

$\mathrm{n}(\%)$

Type of facility

Acute inpatient

Acute outpatient

General practitioner

Nursing home

Specialist Lymphoedema Centre

Gender

Female

Male

Age

Mean (minimum, maximum)

Median

Age groups, years

5-14

$15-44$

45-64

$65-74$

$75-84$

85 plus

Obesity

Under weight

Normal weight

Obese

Morbidly obese

Lower limb mobility

Bed bound

Chair bound

Walks with aid

Walks unaided

Upper limb mobility

No function

Limited range of movement

Full range of movement

Comorbidity

Diabetes mellitus

Heart failure/ischemic heart disease

Neurological disease

Peripheral arterial disease

None of these

Subjective control of swelling

Yes

No
$53(5.04)$

$426(40.53)$

$1(0.10)$

$2(0.19)$

$569(54.14)$

$980(93.24)$

$71(6.76)$

$53.42(7-85)$

54

$5(0.48)$

$231(21.98)$

$615(58.52)$

$161(15.32)$

$38(3.62)$

$1(0.10)$

$14(1.33)$

$630(59.94)$

$357(33.97)$

$50(4.76)$

$10(0.95)$

$13(1.24)$

$71(6.76)$

$957(91.06)$

$3(0.29)$

$138(13.13)$

$910(86.58)$

$210(19.98)$

84 (7.99)

$33(3.14)$

$115(10.94)$

$711(67.65)$

$393(48.70)$

$414(51.30)$ and psychological challenges and impairs the quality of life (QoL) if it is underrecognized and undertreated. ${ }^{3,4}$ Treatment cost of lymphedema has also been identified as a barrier. The support and funding of medical conditions and complex care needs will ease the stress and treatment burden associated with lymphedema. ${ }^{5}$ There are also challenges of managing complex lymphedema patients with obesity, and those associated with chronic medical conditions and wounds. ${ }^{6}$ Therefore the awareness of this chronic condition by both health professionals and patients-knowledge comprising the characteristics of lymphedema patients, difficulties finding appropriate treatments or funding for care, and the impact of disease on functional, psychosocial status, and QoL are of great importance, especially in developing countries.

Lymphedema has been a rising condition in Turkey over the past 10-12 years. Awareness about lymphedema was low and the treatment methods were unknown and certified lymphedema specialists were lacking until recent years. ${ }^{7}$ There are no data about the incidence of lymphedema in Turkey. Patient characteristics or experiences of some patients are reported in some small studies. ${ }^{7-9}$

The LIMPRINT $^{\odot}$ study is an international multisite health service-based study to determine the prevalence and functional impact of lymphedema/chronic edema in the adult population of member countries of the International Lymphoedema Framework (ILF). It aims to estimate the proportion of patients with chronic edema and those with a concurrent wound.

Turkey has been a member of the ILF since 2017 under the auspices of the Anatolian/Turkish Lymphedema Association (ALA), but the LIMPRINT study was first noticed by Dr. Borman, Chair of the ALA at the ILF Meeting in Glasgow, 2014 (www.ilfconference.org). She was influenced by the presentations from other countries and was interested to find out how a study of Turkish lymphedema patients could be made and compare it with different countries. The participation in LIMPRINT study would be valuable and provide important information about the demographic, social, and QoL characteristics of Turkish patients. The study results would show the current status and characteristics of lymphedema patients, treatment conditions, the unmet need for diagnosis and treatment of those suffering with the condition, and burden of the disease in both patients and families in Turkey. The LIMPRINT study would also allow the comparison with different populations from different countries. In addition the data would be informative for developing national health polices and reimbursement procedures in diagnosis and treatment of lymphedema in Turkey.

\section{Materials and Methods}

Considering all these points, an interest in being part of LIMPRINT was shared with the executive members of ALA, and after unanimous approval, a request for Turkey to be involved was officially made in 2014 and accepted by the ILF.

Two main institutions are related to lymphedema in Turkey: Anatolian Lymphedema Association and Hacettepe University Lymphedema Practice and Research Center. Therefore the participation in this international multicenter study proposal was sent to the health professional delegates of the ALA from different parts of Turkey working in centers who are managing patients with lymphedema. In addition, Hacettepe University Lymphedema Practice and Research 
Table 2. The Turkish Edema Characteristics in the Core Tool $(N=051)$

\begin{tabular}{|c|c|c|c|c|}
\hline & Total $(\mathrm{N}=1051)$ & Female $(\mathrm{n}=980)$ & Male $(\mathrm{n}=71)$ & $\chi^{2}(d f)$ or $\mathrm{p}$-value \\
\hline \multicolumn{5}{|l|}{ Classification } \\
\hline Primary & $152(14.48)$ & $129(13.18)$ & $23(32.39)$ & $19.75(1)$ \\
\hline Secondary & $898(85.52)$ & $850(86.82)$ & $48(67.61)$ & $<0.001$ \\
\hline \multicolumn{5}{|l|}{ Secondary swelling } \\
\hline Cancer & $717(79.58)$ & $698(81.92)$ & $19(38.78)$ & $53.09(1)$ \\
\hline Noncancer & $184(20.42)$ & $154(18.08)$ & $30(61.22)$ & $<0.001$ \\
\hline \multicolumn{5}{|c|}{ Cancer-related secondary LE } \\
\hline Treatment related & $715(99.72)$ & $696(99.71)$ & $19(100.0)$ & $0.99^{\mathrm{a}}$ \\
\hline Metastatic & $8(1.12)$ & $7(1.00)$ & $1(5.26)$ & $0.19^{\mathrm{a}}$ \\
\hline \multicolumn{5}{|c|}{ Noncancer-related secondary LE } \\
\hline Venous & $92(50.0)$ & $71(46.10)$ & $21(70.00)$ & 0.017 \\
\hline Immobility & $48(26.09)$ & $36(23.38)$ & $12(40.00)$ & 0.058 \\
\hline Obesity & $84(45.65)$ & $74(48.05)$ & $10(33.33)$ & 0.14 \\
\hline Lymphatic filariasis & $5(2.72)$ & $4(2.6)$ & $1(33.3)$ & $0.99^{\mathrm{a}}$ \\
\hline Noncancer other & $57(30.98)$ & $51(33.12)$ & $6(20.00)$ & 0.16 \\
\hline \multicolumn{5}{|l|}{ Duration } \\
\hline$<6$ Months & $273(26.00)$ & $260(26.56)$ & $13(18.31)$ & \\
\hline 6 Months to 1 year & $128(12.19)$ & $122(12.46)$ & $6(8.45)$ & \\
\hline $1-2$ Years & $142(13.52)$ & $133(13.59)$ & $9(12.68)$ & $6.64(5)$ \\
\hline $2-5$ Years & $219(20.86)$ & $201(20.53)$ & $18(25.35)$ & 0.25 \\
\hline 5-10 Years & $146(13.90)$ & $136(13.89)$ & $10(14.08)$ & \\
\hline $10+$ Years & $142(13.52)$ & 127 (12.97) & $15(21.13)$ & \\
\hline \multicolumn{5}{|l|}{ History of cellulitis } \\
\hline Yes & $232(22.07)$ & $206(21.02)$ & $26(36.62)$ & $9.37(1)$ \\
\hline No & $819(77.93)$ & $774(78.98)$ & $45(63.38)$ & 0.002 \\
\hline \multicolumn{5}{|l|}{ Infection in last year } \\
\hline Yes & $171(73.71)$ & $149(72.33)$ & $22(84.62)$ & $1.80(1)$ \\
\hline No & $61(26.29)$ & $57(27.67)$ & $4(15.38)$ & 0.18 \\
\hline \multicolumn{5}{|l|}{ Lower limb swelling } \\
\hline Yes & $426(40.57)$ & 367 (37.49) & $59(83.10)$ & $57.12(1)$ \\
\hline No & $624(59.43)$ & $612(62.51)$ & $12(16.90)$ & $<0.001$ \\
\hline \multicolumn{5}{|l|}{ Upper limb swelling } \\
\hline Yes & $628(59.81)$ & $615(62.82)$ & $13(18.31)$ & $54.56(1)$ \\
\hline No & $422(40.19)$ & $364(37.18)$ & $58(81.69)$ & $<0.001$ \\
\hline
\end{tabular}

${ }^{a}$ Fisher's exact test.

LE, lymphedema.

Center actively engaged and recruited a great number of patients in collaboration with the Department of Physical Medicine and Rehabilitation. Vascular surgeons and nurses were also informed. Most of the surgeons were not interested in joining the study. After this initial information the proposal was sent to 10 centers with 8 accepting to be part of the study.

The local steering groups were Anatolian (Turkish) Lymphedema Association and Hacettepe University Lymphedema Practice and Research Center. The stakeholders were as follows, from five different areas of the country:

(1) University of Hacettepe Faculty of Medicine Department of Physical Medicine and Rehabilitation (PMR) and Hacettepe University Lymphedema Research and Practice Center (Dr. Pinar Borman, Dr. Merve Denizli, Dr. Ayşegül Yaman, Dr. Oya Özdemir, Dr. Fusun Terzioğlu, and Ayşe Arikan Dönmez).

(2) Ankara Rehabilitation Training and Research Hospital (Dr. Meltem Vural, Dr. Sibel Ünsal Delialioğlu).

(3) Ankara Training and Research Hospital Clinic of PMR (Dr. Figen Ayhan, Dr. Burcu Duyur Çakıt, Dr. Seçil Vural).
(4) Kirsehir Ahi Evran University Department of PMR (Dr. Eda Kurt).

(5) Ege University Medical Faculty Department of PMR, Izmir (Dr. Sibel Eyigör).

(6) Istanbul Rehabilitation Training and Research Hospital Clinic of PMR (Dr. Evrim Coşkun Çelik).

(7) Istanbul Kanuni Sultan Süleyman Education and Research Hospital (Dr. Muge Kepekçi).

(8) Manisa Celal Bayar University Medical Faculty Department of PMR (Lale Cerrahoğlu).

All centers gained approval from their local ethical committees. The coordinator of the Turkish study was the chair of ALA and director of the HU Lymphedema Practice and Research Center-P.B. All the LIMPRINT questionnaires were translated to Turkish and back translated to ensure accuracy of language. The QoL questionnaires lymphedema quality of life (LYMQOL)-arm and LYMQOL-leg ${ }^{10}$ did not have Turkish validation. The cross-cultural Turkish validation studies of the LYMQOL-arm and LYMQOL-leg questionnaires were performed before this study began adding further validity to the methods. ${ }^{11,12}$ Then the Turkish data collection forms were sent 
Table 3. The Treatment Categories $(N=051)$

\begin{tabular}{|c|c|c|c|c|}
\hline & $\begin{array}{c}\text { All patient }(\mathrm{N}=1051) \\
\mathrm{n}(\%)\end{array}$ & $\begin{array}{c}\text { Female }(\mathrm{n}=980) \\
\mathrm{n}(\%)\end{array}$ & $\begin{array}{l}\text { Male }(\mathrm{n}=71) \\
\mathrm{n}(\%)\end{array}$ & $\begin{array}{c}\chi^{2}(d f) \text { or } \\
\text { p-value }\end{array}$ \\
\hline \multicolumn{5}{|c|}{ No treatment offered } \\
\hline No & $698(66.41)$ & $652(66.53)$ & $46(64.79)$ & $0.09(1)$ \\
\hline Yes & $353(33.59)$ & $328(33.47)$ & $12(35.21)$ & 0.76 \\
\hline \multicolumn{5}{|c|}{ Skin care advice } \\
\hline No & $552(52.52)$ & $51652.65)$ & $36(50.70)$ & $0.10(1)$ \\
\hline Yes & $499(47.48)$ & $464(47.35)$ & $35(49.30)$ & 0.75 \\
\hline \multicolumn{5}{|c|}{ Wound dressing } \\
\hline No & $1020(97.05)$ & $957(97.65)$ & $63(88.73)$ & $18.40(1)$ \\
\hline Yes & $31(2.95)$ & $23(2.35)$ & $8(11.27)$ & $<0.001$ \\
\hline \multicolumn{5}{|c|}{ Antibiotic } \\
\hline No & $934(88.87)$ & $880(89.80)$ & $54(76.06)$ & $12.63(1)$ \\
\hline Yes & $117(11.13)$ & $100(10.20)$ & $17(23.94)$ & $<0.001$ \\
\hline \multicolumn{5}{|c|}{ Massage } \\
\hline No & $594(56.52)$ & $553(56.43)$ & $41(57.57)$ & $0.04(1)$ \\
\hline Yes & $457(43.48)$ & $427(43.57)$ & $30(42.25)$ & 0.83 \\
\hline \multicolumn{5}{|c|}{ Physiotherapy } \\
\hline No & $963(91.63)$ & $902(92.04)$ & $61(85.92)$ & $3.24(1)$ \\
\hline Yes & $88(8.37)$ & $78(7.96)$ & $10(14.08)$ & 0.07 \\
\hline \multicolumn{5}{|c|}{ Compression garment } \\
\hline No & $638(60.70)$ & $599(61.12)$ & $39(54.93)$ & $1.06(1)$ \\
\hline Yes & $413(39.30)$ & $381(38.88)$ & $32(45.07)$ & 0.30 \\
\hline \multicolumn{5}{|c|}{ Multilayer bandage } \\
\hline No & $716(68.13)$ & $669(68.27)$ & $47(66.20)$ & $0.13(1)$ \\
\hline Yes & $335(31.87)$ & $311(31.73)$ & $24(33.80)$ & 0.72 \\
\hline \multicolumn{5}{|c|}{ Pneumatic compression pumps } \\
\hline No & $903(85.92)$ & $846(86.33)$ & $57(80.28)$ & $2.00(1)$ \\
\hline Yes & $148(14.08)$ & $134(13.67)$ & $14(19.72)$ & 0.16 \\
\hline \multicolumn{5}{|c|}{ Debulking-lipedema-lymphatic surgery } \\
\hline No & $1042(99.14)$ & $971(99.08)$ & $71(100.00)$ & \\
\hline Yes & $9(0.86)$ & $9(0.92)$ & $0(0)$ & $0.99^{\mathrm{a}}$ \\
\hline \multicolumn{5}{|c|}{ Exercise advice } \\
\hline No & $517(49.19)$ & $479(48.88)$ & $38(53.52)$ & $0.57(1)$ \\
\hline Yes & $534(50.81)$ & $501(51.12)$ & $33(46.48)$ & 0.45 \\
\hline \multicolumn{5}{|c|}{ Cellulitis advice } \\
\hline No & $811(77.16)$ & $761(77.65)$ & $50(70.42)$ & $1.96(1)$ \\
\hline Yes & $240(22.84)$ & $219(22.35)$ & $21(29.58)$ & 0.16 \\
\hline \multicolumn{5}{|c|}{ Psychological support } \\
\hline No & $963(91.63)$ & $900(91.84)$ & $63(88.73)$ & $0.83(1)$ \\
\hline Yes & $88(8.37)$ & $80(8.16)$ & $8(11.27)$ & 0.36 \\
\hline \multicolumn{5}{|c|}{ Complex decongestive therapy } \\
\hline No & $1035(98.48)$ & 965 (98.47) & $70(98.59)$ & $0.99^{\mathrm{a}}$ \\
\hline Yes & $16(1.52)$ & $15(1.53)$ & $1(1.41)$ & \\
\hline \multicolumn{5}{|c|}{ Control of swelling } \\
\hline No & $414(51.30)$ & $372(49.80)$ & $42(70.00)$ & $9.07(1)$ \\
\hline Yes & $393(48.70)$ & $375(50.20)$ & $18(30.00)$ & 0.003 \\
\hline
\end{tabular}

${ }^{\text {a}}$ Fisher's exact test.

to the included centers. All the centers filled the questionnaires and sent them by ordinary mail to the coordinator and they were then returned when completed in batches of 30. Data entry was undertaken from one center (Hacettepe University) with each center given an individual code.

The patients were recruited to the study according to the inclusion and exclusion criteria of the LIMPRINT study protocol. Data were collected using a Core Tool to determine the prevalence of chronic edema and a set of five Module Tools to assess the impact of chronic edema on the lives of sufferers. Data were entered into a secure central on-line database. The core tools included questions about type of facility in which data are collected, demographics, level of obesity, mobility, relevant comorbidities, classification and history of lymphedema, cellulitis history, categories of treatment, site of swelling, wound area, access to treatment, and subjective control of swelling. The module tools comprised demographics and disability, QoL, details of swelling, wounds, and cancer. The Turkish version of World Health Organization Disability Assessment Schedule 2.0 (WHODAS 
Table 4. The Questions Related to Access, Distance, and Patient Costs of Treatment $(N=009)$

\begin{tabular}{|c|c|c|c|c|}
\hline & Total $(\%)$ & Female (\%) & Male (\%) & $\chi^{2}(d f)$ or $\mathrm{p}$-value \\
\hline \multicolumn{5}{|c|}{ (1) Are patients' entire treatment complex decongestive therapy free? } \\
\hline Yes & $779(77.21)$ & $730(77.49)$ & $49(73.13)$ & $0.68(1)$ \\
\hline No & $230(22.79)$ & $212(22.51)$ & $18(26.87)$ & 0.41 \\
\hline \multicolumn{5}{|c|}{ (2) If it is not free, could the patient cover the treatment expenses? } \\
\hline Yes & $538(61.14)$ & $504(61.61)$ & $34(54.84)$ & $1.11(1)$ \\
\hline No & $342(38.86)$ & $314(38.39)$ & $28(45.16)$ & 0.29 \\
\hline \multicolumn{5}{|c|}{ (3) Is lymphedema treatment available in a reasonable distance? } \\
\hline Yes & $785(77.95)$ & $753(80.02)$ & $32(48.48)$ & $35.69(1)$ \\
\hline No & $222(22.05)$ & $188(19.98)$ & $34(51.52)$ & $<0.001$ \\
\hline \multicolumn{5}{|c|}{ (4) Does the distance prevent the patient from accessing a specialist center? } \\
\hline Yes & $302(36.39)$ & $276(35.84)$ & $26(43.33)$ & $1.35(1)$ \\
\hline No & $528(63.61)$ & $494(64.16)$ & $34(56.67)$ & 0.25 \\
\hline \multicolumn{5}{|c|}{ (5) Do patients' lymphedema/wounds prevent discharge from hospital? } \\
\hline Yes & $47(10.26)$ & $35(8.47)$ & $12(26.67)$ & $14.58(1)$ \\
\hline No & $411(89.74)$ & $378(91.53)$ & $33(73.33)$ & $<0.001$ \\
\hline \multicolumn{5}{|c|}{ (6) Is the patient's lymphedema/wound the main reason for remaining in long-term care? } \\
\hline Yes & $79(17.59)$ & $63(15.40)$ & $16(40.00)$ & $15.20(1)$ \\
\hline No & $370(82.41)$ & $346(84.60)$ & $24(60.00)$ & $<0.001$ \\
\hline \multicolumn{5}{|c|}{ (7) Is the patient's lymphedema/wound the main reason for remaining in long-term home care? } \\
\hline Yes & $50(11.47)$ & $40(10.05)$ & $10(26.32)$ & $9.04(1)$ \\
\hline No & $386(88.53)$ & $358(89.95)$ & $28(73.68)$ & 0.003 \\
\hline
\end{tabular}

2.0) was used to assess disability, ${ }^{13,14}$ and LYMQOL ${ }^{10-12}$ and European Quality of Life Five Dimensional Questionnaire (EQ-5D) ${ }^{15,16}$ tools were used to assess QoL.

WHODAS 2.0 is a validated 12 -item disability assessment schedule. It includes questions exploring the patient's personal circumstances for example, housing, employment, and education. $^{14,15}$

LYMQOL is a validated condition-specific QoL assessment instrument (it is not validated for patients with lymphatic filariasis) that assesses the impact of lymphedema on the patient's everyday living and health-related QoL. There is a tool for patients with lymphedema of the upper limb and one for the lower limb. ${ }^{11-13}$

EQ-5D is a generic QoL instrument applicable to a wide range of health conditions and provides a simple descriptive profile and single index value for health status. ${ }^{15} \mathrm{EQ}-5 \mathrm{D}$ is primarily intended for self-completion and is simple and quick to complete. Turkish validation has previously been made and used in this study. ${ }^{16}$

\section{Results}

A total of 1051 patients from eight centers of five different geographical areas took part in the study. Most of the patients were recruited from specialist lymphedema services. The majority of patients were women, housewives, nonobese, had full range of movement, and walked independently. The most common comorbidity was diabetes followed by hypertension. Half the patients stated that their edema was not under control. The core demographic properties of the patients are given in Table 1.

The classification of lymphedema was mostly secondary ( $85 \%)$ and caused by cancer $(79 \%)$ with $85 \%$ suffering from breast cancer, followed by venous insufficiency, lipedema, immobility, and obesity. The cellulitis and infection or hospitalization for cellulitis and infection were infrequent.
The duration of lymphedema was $<5$ years in majority of the patients. The whole group disease characteristics and distribution of variables according to gender are given in Table 2.

The treatment categories of the patients are given in Table 3. The majority of patients did not get any treatment or advice before $(66.4 \%)$. The most common treatment was exercise $(50 \%)$, skin care advice $(47 \%)$, massage $(43 \%)$, and compression garment (40\%). Psychological support was neglected in $91 \%$ of patients. A great number of patients expressed that their swelling was not under control. In Turkey the complex decongestive therapy is free in government hospitals for patients with obligative health insurance. Therefore the majority of the attendants replied to this question that treatment was free. But the cost of bandages for multilayer short stretch bandaging are not reimbursed and the amount of compression garments are only partially reimbursed in Turkey. Nearly $40 \%$ of the patients stated that if the treatment was not free, they could not cover the expenses for the treatment. Most of the patients suggested that lymphedema treatment was available for free within a reasonable travelling distance, as they are living in big cities or metropoles, but more than one third of them declared that the distance would prevent patients from accessing specialized centers. As the majority of patients did not have wounds or complicated lymphedema, they were not related to discharge from hospital or long stays in care centers (Table 4).

According to the demographics in the module data, most patients were in the age range of 45-64 years and were living with their partners or relatives. Eighty percent of the patients were owner occupiers and $55 \%$ had their own vehicle. As most of the patients were housewives, they were not the main provider for their family. Fifty-two percent of the attendants had primary school education with only $20 \%$ having a university diploma. As most patients were housewives $(55 \%)$, they $(92 \%)$ did not have to change or 
Table 5. Demographic Characteristics $(N=048)$

\begin{tabular}{|c|c|}
\hline & $\mathrm{n}(\%)$ \\
\hline \multicolumn{2}{|l|}{ Living with } \\
\hline No one/live alone & $109(10.4)$ \\
\hline Partner/spouse & 724 (69.1) \\
\hline Other relative & $212(20.2)$ \\
\hline Friend & $2(0.2)$ \\
\hline Other & $1(0.1)$ \\
\hline \multicolumn{2}{|l|}{ Living accommodation } \\
\hline Owner occupier & $838(80)$ \\
\hline Public rented & $11(1.1)$ \\
\hline Privately rented & $189(18)$ \\
\hline Nursing home & $5(0.5)$ \\
\hline Hospital ... & $1(0.1)$ \\
\hline $\begin{array}{l}\text { Supported living } \\
\text { accommodation }\end{array}$ & $4(0.4)$ \\
\hline \multicolumn{2}{|l|}{ Patients who had a car or other vehicle } \\
\hline Yes & $582(55.5)$ \\
\hline No & $466(44.5)$ \\
\hline \multicolumn{2}{|l|}{ Working/job } \\
\hline Employed full time & $148(14.1)$ \\
\hline Employed part time & $25(2.4)$ \\
\hline Retired & $208(19.8)$ \\
\hline Unemployed looking for work & $20(1.9)$ \\
\hline Not working because of illness & $68(6.5)$ \\
\hline $\begin{array}{l}\text { Looking after the house } \\
\text { (housewives) }\end{array}$ & $581(55.4)$ \\
\hline $\begin{array}{l}\text { Full or part-time education } \\
\text { or training }\end{array}$ & $15(1.4)$ \\
\hline Other & $3(0.3)$ \\
\hline \multicolumn{2}{|l|}{ Patients were the main provider } \\
\hline Yes & $202(19.3)$ \\
\hline No & $846(80.7)$ \\
\hline $\begin{array}{l}\text { Age of graduation, mean } \pm \mathrm{SD}, \\
\text { median (minimum to maximum) }\end{array}$ & $16.3 \pm 4.9,17(8-45)$ \\
\hline \multicolumn{2}{|l|}{ Degree of graduation } \\
\hline None (elementary school) & $549(52.4)$ \\
\hline School certificate/diploma & $265(25.3)$ \\
\hline University diploma/degree & $215(20.5)$ \\
\hline Master's degree & $9(0.9)$ \\
\hline Doctorate & $10(1)$ \\
\hline \multicolumn{2}{|l|}{$\begin{array}{l}\text { Patients who had to change their } \\
\text { job or education/training }\end{array}$} \\
\hline Yes & $52(5)$ \\
\hline No & $996(95)$ \\
\hline \multicolumn{2}{|l|}{$\begin{array}{l}\text { Patients who had to stop work or } \\
\text { education/training }\end{array}$} \\
\hline Yes & $82(7.8)$ \\
\hline No & $966(92.2)$ \\
\hline \multicolumn{2}{|c|}{$\begin{array}{l}\text { Patients who had been affected/reduced } \\
\text { their family income because } \\
\text { of the swelling }\end{array}$} \\
\hline Yes & $99(9.5)$ \\
\hline No & $949(90.6)$ \\
\hline
\end{tabular}

stop their job/work that would affect their family income (Table 5).

The details of swelling in the module data are given in Table 6. The site of swelling was the upper extremity (arms) in $59 \%$ followed by legs $(39.8 \%)$, Overall $55 \%$ did not have
Table 6. Details of Swelling $(N=050)$

\begin{tabular}{lc}
\hline & $\mathrm{n}(\%)$ \\
\hline Pitting & \\
Yes & $475(45.2)$ \\
No & $575(54.8)$ \\
Tissue in swollen area & \\
Soft & $715(68.1)$ \\
Hard & $335(31.9)$ \\
Shape distortion in the affected limb & \\
Yes & $436(41.5)$ \\
No & $614(58.5)$ \\
Patients who had been told the reason for the & \\
swelling & $671(63.9)$ \\
Yes & $379(36.1)$ \\
No & \\
The site of swelling & $617(59.0)$ \\
Arm & $416(39.8)$ \\
Leg & $12(1.2)$ \\
Both & \\
Stemmers sign & $313(49.3)$ \\
Hand-positive & $329(75.8)$ \\
Foot-positive & \\
Severity of the swelling & $289(27.5)$ \\
ISL stage I & $648(61.7)$ \\
ISL stage II & $113(10.8)$ \\
ISL stage III & \\
\hline
\end{tabular}

ISL, International Society of Lymphology.

pitting edema. Tissues in the swollen area were mostly soft with $41 \%$ having a significant shape distortion. Thirty-six percent of the patients had not been told the reason for the swelling. Stemmer sign was positive in $75 \%$ of patients with lower extremity and $49 \%$ of patients in upper extremity

Table 7. The Disability and Quality-Of-Life SCORES $(N=050)$

\begin{tabular}{lccc}
\hline & Mean $\pm S D$ & Median & $\begin{array}{c}\text { Minimum } \\
\text { to maximum }\end{array}$ \\
\hline WHODAS overall & $31.7 \pm 21.8$ & 27.1 & $0-100$ \\
scores $N=1050$ & & & \\
EQ-5D scores & $0.56 \pm 0.32$ & 0.62 & $0.59-1$ \\
$\quad(n=1050)$ & & & \\
Overall health & $61.2 \pm 20.5$ & 60 & $0-100$ \\
scores $(n=1050)$ & & & \\
LYMQOL-upper & & & \\
extremity $(n=630)$ & & & \\
Function & $17.5 \pm 6.1$ & 16 & $10-40$ \\
Appearance & $9.4 \pm 3.6$ & 9 & $5-20$ \\
Symptoms & $12.3 \pm 4$ & 12 & $6-24$ \\
Emotion & $11.3 \pm 4.2$ & 11 & $6-24$ \\
Overall & $6.6 \pm 1.8$ & 7 & $0-10$ \\
LYMQOL-lower & & & \\
extremity $(n=429)$ & & & \\
Function & $19.1 \pm 6.4$ & 19 & $8-32$ \\
Appearance & $17.5 \pm 5.9$ & 17 & $7-28$ \\
Symptoms & $11.8 \pm 3.9$ & 11 & $5-20$ \\
Emotion & $12.9 \pm 4.5$ & 12 & $6-24$ \\
Overall & $5.1 \pm 2.1$ & 5 & $0-10$ \\
\hline
\end{tabular}

EQ-5D, European Quality of Life Five Dimensional Questionnaire; LYMQOL, lymphedema quality of life; WHODAS, World Health Organization Disability Assessment Schedule. 
Table 8. Details of Cancer $(N=15)$

\begin{tabular}{|c|c|}
\hline & $\mathrm{N}(\%)$ \\
\hline \multicolumn{2}{|c|}{ Patients who had treatment for cancer } \\
\hline Yes & 710 \\
\hline No & 5 \\
\hline \multirow{3}{*}{\multicolumn{2}{|c|}{$\begin{array}{l}\text { Duration between swelling and cancer } \\
\text { treatment (How long after the cancer } \\
\text { treatment did you develop swelling } \\
\text { in the affected area?) }\end{array}$}} \\
\hline & \\
\hline & \\
\hline$<3$ Months & $152(21.3)$ \\
\hline 3-11 Months & $234(32.7)$ \\
\hline $1-5$ Years & $249(34.8)$ \\
\hline 6-9 Years & $40(5.6)$ \\
\hline $10+$ Years & $32(4.5)$ \\
\hline Unknown & $5(0.7)$ \\
\hline Not applicable & $3(0.4)$ \\
\hline \multicolumn{2}{|l|}{ Current cancer status } \\
\hline Cured/remission & $229(32.0)$ \\
\hline Local cancer & $383(53.6)$ \\
\hline Distant metastases & $56(7.8)$ \\
\hline Do not know & $47(6.6)$ \\
\hline \multicolumn{2}{|l|}{ Type of cancer } \\
\hline Bladder cancer & $2(0.3)$ \\
\hline Breast cancer & $603(84.3)$ \\
\hline Cervical cancer & $20(2.8)$ \\
\hline Colorectal cancer & $2(0.3)$ \\
\hline Endometrial cancer & $57(8.0)$ \\
\hline Head and neck cancer & $1(0.1)$ \\
\hline Melanoma cancer & $6(0.8)$ \\
\hline Ovarian cancer & $17(2.4)$ \\
\hline Vulval cancer & $2(0.3)$ \\
\hline Other cancer & $16(2.2)$ \\
\hline \multicolumn{2}{|l|}{ Type of cancer treatments } \\
\hline Surgery & $703(98.3)$ \\
\hline Radiation therapy & $569(79.6)$ \\
\hline Chemotherapy & $595(83.2)$ \\
\hline Hormone therapy & $306(42.8)$ \\
\hline Molecular target therapy & $16(2.2)$ \\
\hline Other & $1(0.1)$ \\
\hline
\end{tabular}

swelling. The majority had ISL grade 2 swelling $(61.7 \%)$ and $27.5 \%$ had ISL grade 1 lymphedema. The disability and QoL scores are given in Table 7. Most of the patients had impaired QoL and decreased functionality. These were prominent especially in lower limb chronic edema patients.

The cancer data showed the majority $(84 \%)$ had breast cancer followed by endometrium ( $8 \%)$, cervix $(2.8 \%)$, and ovarian $(2.4 \%)$ cancers. All but five of them had received treatment for cancer, with $53 \%$ having local cancer and $32 \%$ being in remission. The most common type of cancer treatment was surgery followed by chemotherapy and radiation therapy. The duration of lymphedema was $<5$ years in the majority of the patients $(88.8 \%)$. Twenty-one percent of patients developed swelling within 3 months, $32 \%$ in $3-11$ months, and $34 \%$ developed in 1-5 years after cancer treatment. The summary of cancer data is given in Table 8 .

The majority of patients $(98 \%)$ did not have a wound. Of the patients with wounds, $55 \%$ had one to two wounds mostly grade 2 small venous ulcers with low exudate located in the legs. Most patients looked after their own wounds followed by physicians and hospital nurses. Nearly half of the wounds
Table 9. Details of Wounds $(N=1)$

\begin{tabular}{lc}
\hline & $\mathrm{N}(\%)$ \\
\hline $\begin{array}{l}\text { Provider wound care } \\
\text { Physician }\end{array}$ & $13(61.9)$ \\
Podiatrist & 0 \\
Self-care & $14(66.7)$ \\
Family/friend & $6(28.6)$ \\
Hospital nurse & $11(52.4)$ \\
Practice nurse & 0 \\
Care home nurse & $2(9.5)$ \\
Wound care specialist nurse & 0 \\
Home care/community nurse & $1(4.8)$ \\
Lymphedema specialist nurse/therapist & $1(4.8)$ \\
Other & 0
\end{tabular}

No. of wounds

One

$7(33.3)$

Two

$9(42.9)$

Three

$2(9.5)$

$1(4.8)$

$1(4.8)$

Five

Six

Missing

$1(4.8)$

$1(4.8)$

Pressure ulcer

None

13

Grade 1

Grade 2

Grade 3

0

$5(62.5)$

Grade 4

$2(25.0)$

1 (12.5)

Leg/foot ulcer cause

No leg/foot ulcer

6

Venous ulcer

Arterial ulcer

Mixed (venous/arterial)

$6(40.0)$

$1(6.7)$

$1(6.7)$

$1(6.7)$

0

Neuroischemic

Other foot ulcer

$2(13.3)$

Do not know ulcer type

7 (46.7)

Acute/surgical wound

No acute/surgical wound

10

Primary closure

Open surgical wound

Postsurgical breakdown

Dehisced wound

Traumatic wound

Do not know wound type

0
0

$2(18.2)$

$5(45.5)$

$2(18.2)$

2 (18.2)

Exudate level

None

$9(42.9)$

Low

7 (33.3)

Medium

$4(19.1)$

High

$1(4.8)$

Location of the wounds

Head or neck

$21(100)$

Arms

$21(100)$

Chest

$19(90.5)$

Abdomen

$21(100)$

Back

$20(95.2)$

Sacrum

$21(100)$

Hips

Upper leg

21 (100)

20 (95.2)

Groin

21 (100)

Lower leg/ankle 9 (42.9)

Foot

14 (66.7)

Other

$20(95.2)$ 
TABle 9. (CONTINUed)

\begin{tabular}{lc}
\hline & $\mathrm{N}(\%)$ \\
\hline Wound area & \\
Small: $<10 \mathrm{~cm}^{2}$ & $17(81)$ \\
Medium: $>10$ and $<25 \mathrm{~cm}^{2}$ & $4(19.1)$ \\
Large: $>25 \mathrm{~cm}^{2}$ & 0 \\
Closed surgical wound & 0 \\
Not applicable & 0 \\
Wound duration & \\
Primary & $16(76.2)$ \\
Recurrent & $5(23.8)$ \\
Time/duration of wounds & \\
<1 Week & 0 \\
1-2 Weeks & $2(9.5)$ \\
2-4 Weeks & $2(9.5)$ \\
4-6 Weeks & $3(14.3)$ \\
6 Weeks to $<3$ months & $4(19.1)$ \\
3 Months to $<6$ months & $3(14.3)$ \\
6 Months to $<1$ year & $1(4.8)$ \\
1 Year to $<5$ years & $3(14.3)$ \\
5 Years or more & $1(4.8)$ \\
Do not know & $2(9.5)$ \\
Wound infection & \\
Yes & $9(42.9)$ \\
No & $10(47.6)$ \\
Unknown & $2(9.5)$ \\
Frequency of dressing change & \\
Twice daily & $6(28.6)$ \\
Daily & $6(28.6)$ \\
Alternate days & $3(14.3)$ \\
Two to three times per week & $5(23.8)$ \\
Once a week & $1(4.8)$ \\
Other & 0 \\
\hline
\end{tabular}

did not have signs of infection (47\%) and had been present $<6$ months in the majority of the patients $(70 \%)$. The wound details are given in Table 9.

One of the fundamental aims of the ILF is to support countries in the development of data to establish the size of the problem of chronic edema. Such data are essential in supporting the introduction of evidence-based practice and enabling each national framework to argue for appropriate financing and reimbursement. ${ }^{17}$ According to the aims of LIMPRINT as an international epidemiological research study; the preliminary demographic results of this study provided evidence-based data for the demographic and clinical properties of Turkish lymphedema patients. The LIMPRINT study brought a great opportunity and vision to our community. The reimbursement of pressure garments was very low in grades 2 and 3 lymphedema patients in Turkey. The ALA have prepared a file for reimbursement of care about the condition and impact of lymphedema based on the results of the LIMPRINT-Turkey study. As a partner of the ILF and of the LIMPRINT study, ALA have summarized and indicated the characteristics of Turkish lymphedema patients and demonstrated their efforts for increasing the awareness and collaboration between health professionals on a national basis. The Turkish Social Security Institution has had meetings with ALA members, made rectification, and taken the decision to pay more for the reimbursement of pressure garments for lymphedema patients with grades 2 and 3 lymphedema. We believe that the final data indicate not only the size of the problem but also the impact of chronic edema on patient lives in terms of functionality and QoL. This will assist lymphedema services to provide evidencebased care. The Turkish LIMPRINT study results demonstrate that many patients cannot access treatment services because of the distance and cannot afford to pay for costly treatments as these are not completely reimbursed. We hope this evidence-based data will change the national policies for the care of Turkish patients with lymphedema or chronic edema.

\section{Conclusion}

This final LIMPRINT data reflect that upper extremity lymphedema is more common than lower extremity and the major cause is cancer treatment, predominantly breast cancer in the Turkish LIMPRINT. The most striking results are that the patients suffer for a long time, most of the patients have uncontrolled lymphedema mostly grade 2 and have not received any previous treatment before the study. Turkish patients had less wounds compared with other studies undertaken in the LIMPRINT study. This is most certainly because of the center characteristics that were rehabilitation services treating a high proportion of cancer patients, particularly breast cancer, rather than dermatology or vascular surgery services. The majority of patients had reduced functional status and decreased QoL. Although most of the patients had social health security for free complex decongestive therapy treatment, their ability to access these centers was more difficult than previously estimated. National health policies and planning are needed for the prevention, diagnosis, and treatment of those suffering this neglected condition in Turkish patients.

\section{Author Disclosure Statement}

No competing financial interests exist.

\section{References}

1. International Society of Lymphology. The diagnosis and treatment of peripheral lymphedema. 2013 Consensus Document of the International Society of Lymphology. Lymphology 2013; 46:1-11.

2. Borman P. Lymphedema diagnosis, treatment, and followup from the view point of physical medicine and rehabilitation specialists. Turk J Phys Med Rehab 2018; 64:179197.

3. Keast DH, Despatis M, Allen JO, Brassard A. Chronic oedema/lymphedema: Under-recognized and under-treated. Int Wound J 2015; 12:328-333.

4. Tzani I, Tsichlaki M, Zerva E. Papathanasiou G, Dimakakos E. Physiotherapeutic rehabilitation of lymphedema: State-of-the-art. Lymphology 2018; 51:1-12.

5. Sierla R, Black D, Mun LEE TS, Killbreath S. Access to treatment for breast cancer-related lymphoedema in Australia. Aust Fam Physician 2013; 42:892-895.

6. Morgan PA, Murray S, Moffatt CJ, Honnor A. The challenges of managing complex lymphoedema/chronic oedema in the UK and Canada. Int Wound J 2012; 9: 54-69. 
7. Borman P, Yaman A, Yasrebi S, Ozdemir O. The importance of awareness and education in patients with breast cancerrelated lymphedema. J Cancer Educ 2017; 32:629-633.

8. Ozaslan C, Kuru B. Lymphedema after treatment of breast cancer. Am J Surg 2004; 187:69-72.

9. Müezzinler NE, Karayurt O. Investigation of experiences of women who developed lymphedema related to breast cancer treatment. J Breast Health 2014; 10:23-29.

10. Keeley V, Crooks S, Locke J, Veigas D, Riches K, et al. A quality of life measure for limb lymphedema (LYMQOL). J Lymphoedema 2012; 5:26-37.

11. Borman P, Yaman A, Denizli M, Karahan S, Özdemir O. The reliability and validity of Lymphedema Quality of Life Questionnaire-Arm in Turkish patients with upper limb lymphedema related with breast cancer. Turk J Phys Med Rehab 2018; 64:205-212.

12. Borman P, Denizli M, Yaman A, Karahan S. The reliability and validity of lymphedema quality of life questionnaireLeg (LYMQOL-Leg) in Turkish Patients with lower limb lymphedema. In 8th International Lymphedema Framework Conference, Rotterdam, Netherlands, June 6-9, 2018, Programme and Abstract Book, p:43. 2018ilfconference .org Accessed April 2, 2019.

13. World Health Organization Disability Assessment Schedule II (2001). Available at www.who.int/icidh/whodas Accessed April 2, 2019.
14. Kutlay S, Küçükdeveci AA, Elhan AH, Oztuna D, Koç N, Tennant A. Validation of the World Health Organization disability assessment schedule II (WHODAS-II) in patients with osteoarthritis. Rheumatol Int 2011; 31:339-346.

15. Devlin NJ, Brooks R. EQ-5D and the EuroQoL group: Past, present and future. Appl Health Econ Health Policy 2017; 15:127-137.

16. Oksuz E. Prevalence, risk factors, and preference-based health states of low back pain in a Turkish population. Spine (Phila Pa 1976) 2006; 31:E968-E972.

17. Moffatt CJ, Pinnington LL. Facilitating the development of community based lymphoedema services through clinical education. A report prepared for the East Midlands Health, Innovation and Education Cluster. 2012. Available at http:// emhiec.co.uk/projects/em13-derby-hospital-lymphoedema (accessed December 15, 2013).

Address correspondence to:

Pinar Borman, MD

Department of Physical Medicine and Rehabilitation University of Hacettepe Faculty of Medicine Sihhiye

06100 Ankara Turkey

E-mail: pinarborman@gmail.com 